\title{
Corrigendum
}

\section{Measuring the short-term spillover impact of a product recall on a brand ecosystem}

\section{Robert Mackalski}

Jean-Francois Belisle

Journal of Brand Management (2015) 22, 485. doi:10.1057/bm.2015.23;

published online 7 August 2015

Correction to: Journal of Brand Management (2015) doi: 10.1057/bm.2015.19;

Published online 10 July 2015

This article has been corrected as of 21 July 2015 to reflect the author's affiliation which was erroneously removed. This has not affected the research in any way and no other element of the article is under question. The correct affiliation details are shown below:

Jean-Francois Belisle is a Manager, Data Aggregation \& reporting at National Bank of Canada. He specializes in data-driven decision making and digital analytics. Before his current role, he worked as a consultant in strategy and analytics for large companies (P\&G, Bell, Development Bank of Canada and Jean Coutu) and supported entrepreneurial companies through advisory and consulting work. He currently lectures at the MBA-level at Université Laval. He pursued PhD studies in Computational Statistics and Marketing at McGill University, holds a Master degree in Marketing from HEC Montréal, and has a Bachelor in Economics from the Université de Montréal. 